\title{
Procedure for simulation of combustion in the burner device of the low- emission combustion chamber
}

\author{
E.V. GAULTIER, A.A. SHENGALS, A.S. TIKHONOV, O.I. KLYAVIN \\ Leading Research Center "Digital Design and Modeling (Smart Design)" \\ Peter the Great St.Petersburg Polytechnic University \\ 195251, St.Petersburg, Polytechnicheskaya, 29 \\ RUSSIA
}

\begin{abstract}
This article discusses the problems of gas dynamic processes modeling in the design of burner devices of low-emission combustion chambers of gas turbine engines. Characteristic features of existing physical and mathematical combustion models, turbulence and radiant heat exchange are analyzed. The necessity of developing a technique that allows developing a final model based on existing physical and mathematical models of turbulence, combustion, radiant heat exchange, and chemical kinetics mechanisms, that accurately reflects gas dynamic processes in burner device of low-emission combustion chamber and allows performing practical calculations with a given accuracy, is identified and justified.

To achieve this goal, the authors suggest the following:

- to conduct filed tests of the burner device under study;

- to perform three-dimensional gas dynamic calculations of the burner device under study using the most used models of turbulence, combustion and radiation;

- based on the results of calculations and field tests, to perform validation and select the most appropriate models for the formation of the final physical and mathematical model of the burner device under study;

- using the final physical and mathematical model to solve a practical problem in order to test the developed simulation procedure.
\end{abstract}

Key-Words: - Gas turbine engine, low-emission combustion chamber, burner device, computer engineering, digital design, numerical simulation, virtual tests, turbulence model, combustion model, radiant heat exchange model, chemical kinetics mechanism.

Received: March 31, 2020. Revised: September 2, 2020. Accepted: September 14, 2020. Published: September 29, 2020.

\section{Introduction}

Despite the currently formed criteria and analytical relationships for the design of various types of burner devices, it is difficult to carry out design refinement without a detailed understanding of the processes inside the burner device, and the process of experimental research is usually long and expensive.

The use of computational gas dynamics methods for calculating gas flow parameters effectively complements the design criteria and analytical relationships, which significantly reduces the amount of expensive experimental work.

The use of computational gas dynamics methods does not eliminate the need for experimental research but increases the quality of technical solutions and significantly reduces the design time.
Success in the creation of burner devices is achieved by a combination of computational and experimental approaches.

Despite the presence of many computational gas dynamics programs, their successful application in design practice requires solving a number of problems due to the characteristic features of gas dynamic and chemical processes in each specific type of burner device.

Combustion simulation is a combination of heterogeneous physical and mathematical models describing such processes as turbulent heat-mass transfer, flame front propagation, chemical reaction kinetics, radiation and heat exchange with the walls of the burner device.

For each of the considered physical phenomena, there are a large number of mathematical models of limited application, which does not allow us to 
formulate a universal approach to simulation that is suitable for any type of burner device.

The number of possible combinations of existing models is very large, even excluding their clearly incompatible combinations, so the development of a technique that would allow for a relatively short time to create a combination of physical and mathematical models of processes that allows to correctly model combustion in a specific burner device is an urgent task.

\section{Literature Review}

Research groups in Russia and abroad are engaged in modeling the combustion process of a fuel mixture, and a fairly large number of studies have been devoted to them [1]-[16].

Most of them are devoted to the study of influence of the choice of certain mathematical models of individual physical processes on the results of numerical experiments. Some works analyze combinations of various combustion models with different turbulence models [2]- [7], other works investigate combinations of different combustion models with different mechanisms of chemical kinetics [12], [13], [16], in the third works only the models of radiant heat exchange are studied [8]-[10], in the fourth works combinations of one turbulence model with different combustion models [1], [14] are investigated without taking into account the compressibility of the working medium.

However, the level of modern engineering problems does not allow using a simplified approach to combustion simulation.

Combustion simulation is a complex task that requires a harmonious and correct combination of heterogeneous mathematical models that reflect such aspects of the process as turbulent heat-mass transfer, chemical reactions kinetics, propagation of the flame front, radiation and heat exchange with the walls of the structure and the environment.

Unfortunately, it was not possible to find publicly available works devoted to the study of the mutual influence of all mathematical models (turbulence, combustion, radiation and chemical kinetics mechanisms) on the results of gas-dynamic calculations, which makes it impossible to evaluate and compare the opinions and methods of other researchers.

\section{Methods}

The paper investigated the influence of various mathematical models of turbulence, combustion and radiant heat exchange, as well as various mechanisms of chemical kinetics on the accuracy of gas dynamic calculations results of the burner device of a low-emission combustion chamber.

Three-dimensional gas dynamic calculations were performed using the finite element method in the ANSYS CFX software package. The calculation results accuracy was evaluated based on the results of field tests.

Filed tests of the burner device were carried out on a stand made in the form of a single-burner compartment.

Figure 1 shows the longitudinal section of the burner device under study.

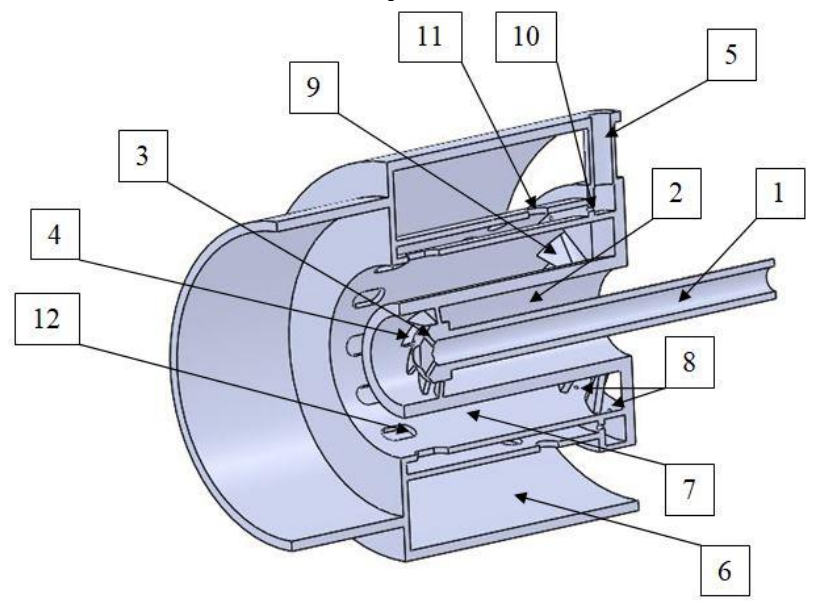

Figure 1. Burner device, section

The studied burner device intended for operation on gaseous fuel (methane), structurally consists of two independent circuits - the first circuit is fed with fuel gas through the channel 1, air through the channel 2, then the fuel gas at the outlet through the holes 3 is mixed with air swirled in the swirler of the first circuit 4 .

To the second circuit fuel gas is supplied via channel 5 and air through channels 6 and 7. Part of the fuel gas of the second circuit is output through the holes 8 to the channel 7 before the blades of the swirler of the second circuit 9, the other part of the fuel gas passing through the holes 10 is mixed with the air coming through the holes 11 and is output through the holes 12 to the channel 7 .

Figure 2 shows a sketch of a single-burner compartment for field tests. 


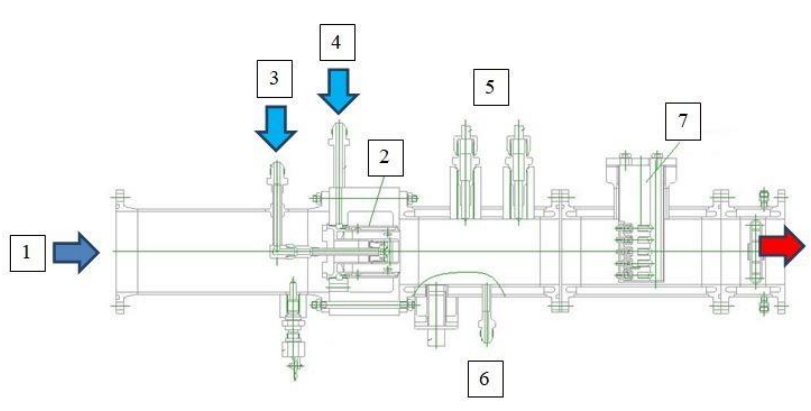

Figure 2. Single-burner compartment

Input 1 in single-burner compartment is supplied with the air of specified parameters - flow rate, total pressure and total temperature, for pipelines 3 and 4 to the first and second circuit of the burner device 2 fuel gas is fed with desired flow rate and temperature. With the help of sensors 5 and 6 , the total temperature and total pressure are measured behind the burner device, and the combustion products are selected for the gas analyzer through the gas receiver 7 .

For carrying out gas dynamic calculations threedimensional geometric model of the design area were made.

Figure 3 shows a geometric model of the flow part of the design area, which is the internal volume of a single-burner section with a burner device installed.

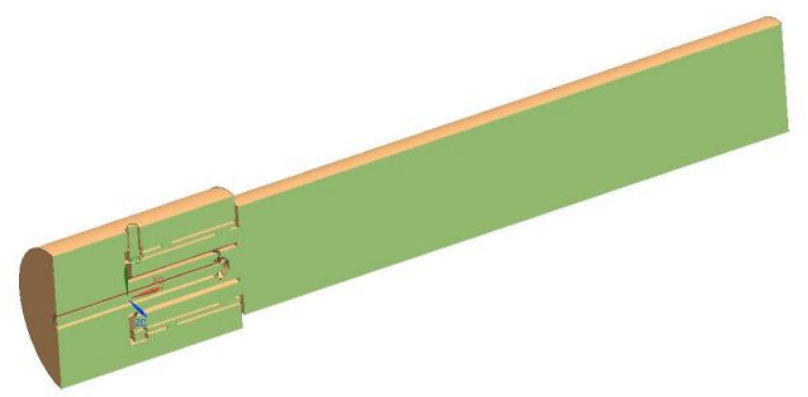

Figure 3. Geometric model of the flow part of the design area, longitudinal section.

In order for the calculation model to correctly display gas-dynamic processes, heat transfer through metal walls between the internal cavities of the flow part and between the flow part and the environment was taken into account. On the basis of a geometric model of the flow part, a geometric model of the burner device and drawing of singleburner section a combined geometric model of the burner device body and the single-burner section body were made shown in figure 4 .

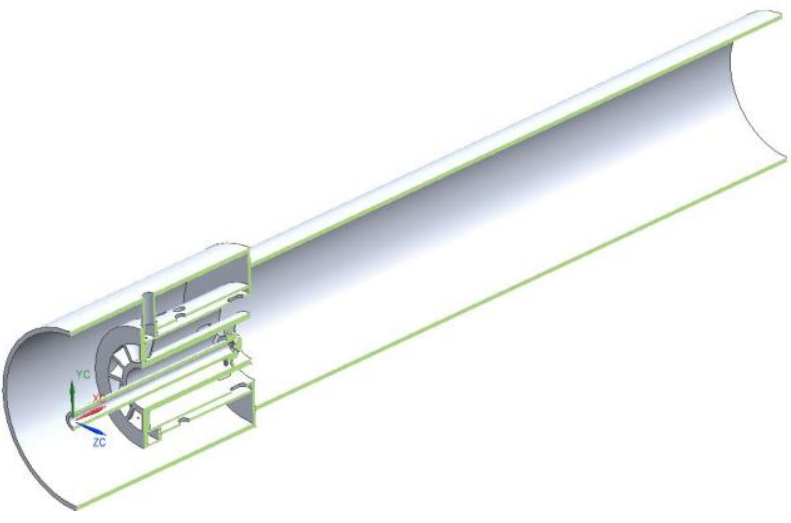

Figure 4. Geometric model of the burner device body and the single-burner section body

The combined geometric model for threedimensional gas dynamic calculations, shown in figure 5, consists of two domains: the flow domain and the body domain.

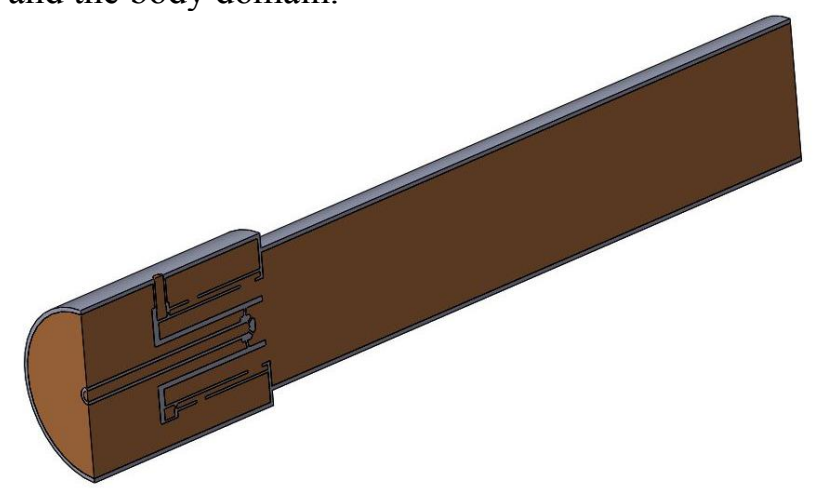

Figure 5. Combined geometric model, longitudinal section

To carry out three-dimensional gas-dynamic calculations by the finite element method based on a geometric model in the Workbench Mesher program of the ANSYS software package, mesh models of the flow part and the body of the single-burner compartment were made. Most of the finite elements of the flow part mesh model are tetrahedrons, the wall layer in the form of prisms was resolved by ten cells in thickness, the minimum element size is $0.05 \mathrm{~mm}$, the maximum element size is $1.2 \mathrm{~mm}$, the average element size on surfaces, except for boundary conditions, is $0.6 \mathrm{~mm}$, the total number of elements is $\sim 10.7$ million.

The grid model of the single-burner section body also consists of tetrahedron, but without prismatic layers, the minimum element size is $0.06 \mathrm{~mm}$, the maximum element size is $1 \mathrm{~mm}$, and the total number of elements is $\sim 3.7$ million.

Calculations were performed in the CFX program of the ANSYS software complex at the supercomputer center of "Peter the Great Saint Petersburg Polytechnic University". 


\section{Results}

The aim of the work was to develop and test a technique for combustion process simulation, which allows, on the basis of existing mathematical models of physical processes, to form a model that reliably reflects gas-dynamic processes in the burner device of a low-emission combustion chamber.

To achieve this goal the authors solved the following tasks:

- filed tests of the burner device under study;

- performance of three-dimensional gas dynamic calculations of the burner device under study, using the most suitable models of turbulence, combustion, radiation and chemical kinetics mechanisms;

- validation of calculation results based on the results of field tests, selection of the most appropriate models for the formation of the final physical and mathematical model of the burner device under study;

- numerical study of the burner device using the generated model to determine the degree of its reliability.

The filed experiment was conducted in two stages - at the first stage, a "cold blowing" was performed to assess the drop in total pressure (hydraulic losses), and at the second stage, fire tests were conducted.

For the filed experiment, air was supplied to the inlet of the single-burner section with a flow rate of $\mathrm{G}_{\mathrm{a}}=0.34 \mathrm{~kg} / \mathrm{sec}$, a full pressure of $\mathrm{P}_{\mathrm{a}}{ }^{*}=1176798 \mathrm{~Pa}$, and a full temperature of $\mathrm{T}_{\mathrm{a}}{ }^{*}=633 \mathrm{~K}$.

The fuel gas inputs were supplied with methane with a flow rate for the first circuit $\mathrm{G}_{\mathrm{fl}}=0.0025$ $\mathrm{kg} / \mathrm{sec}$, for the second circuit $\mathrm{G}_{\mathrm{f} 2}=0.0074 \mathrm{~kg} / \mathrm{sec}$ and a temperature for both circuits $\mathrm{T}_{\mathrm{fl}, 2}=288 \mathrm{~K}$.

The results obtained in the filed experiment are presented in table 1

Table 1. Field tests results

\begin{tabular}{|l|l|l|l|l|}
\hline Stage/Parameter & $\mathrm{P}^{*}, \mathrm{~Pa}$ & $\mathrm{~T}^{*}, \mathrm{~K}$ & $\mathrm{O}_{2} \mathrm{v}, \%$ & $\begin{array}{l}\sigma^{*}, \\
\%\end{array}$ \\
\hline Cold blowing & 1132079.7 & 621.8 & - & 3.8 \\
\hline Fire tests & 1128549.3 & 1732 & 10.51 & 4.09 \\
\hline
\end{tabular}

$\mathrm{P}^{*}, \mathrm{~T}^{*}$ - total pressure and total temperature in the measuring area;

$\mathrm{O}_{2} \mathrm{v}$ - volume content of oxygen in the combustion products in the measuring area.

$\sigma^{*}=\left(\left(\mathrm{P}^{*}{ }_{\text {in.air }}-\mathrm{P}^{*}\right) / \mathrm{P}^{*}\right.$ in.air $) \times 100 \%$ - total pressure loss in $\%$.

Three-dimensional gas dynamic calculations were performed, as well as field tests in two stages. At the first stage of the computational studies, various turbulence models were tested, and at the second stage, combustion models and chemical kinetics mechanisms were tested.
Figure 6 shows the calculation model.

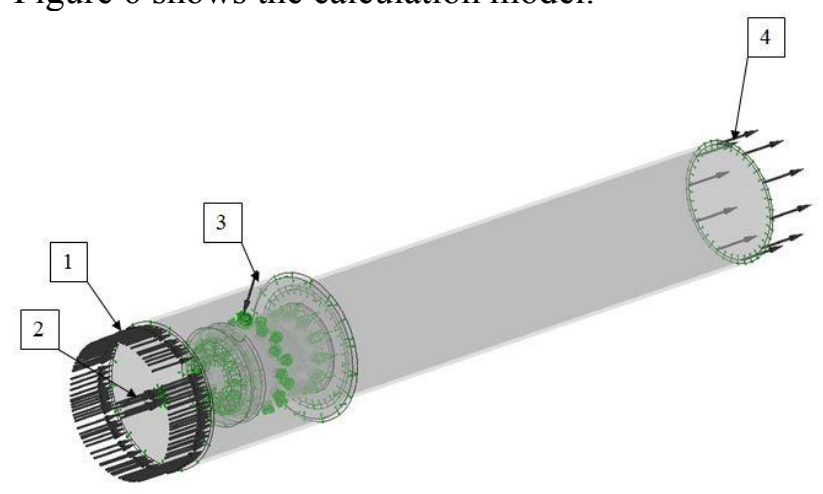

Figure 6. Calculation model

The calculation model consists of two domains: the flow domain, which is a fluid medium, and the body domain, which is defined as a solid. Domains interact with each other through the interface. Heat transfer is taken into account between the outer surface of the body domain and the environment (the heat transfer coefficient is set, and the ambient temperature is $288 \mathrm{~K}$ ).

At inlet 1 , the total pressure $\mathrm{P}^{*}$ in.air and total air temperature $\mathrm{T}^{*}{ }_{\text {in.air }}$ were set, at inputs 2 and 3 , the mass flow rates $G_{\mathrm{f} 1}, \mathrm{G}_{\mathrm{f} 2}$ and static temperatures of the fuel gas (methane) $\mathrm{T}_{\mathrm{fl}, 2}$ were set, at output 4 (Gin.air $+\mathrm{G}_{\mathrm{f} 1}+\mathrm{G}_{\mathrm{f} 2}$ ), calculations were performed in the mode corresponding to the conditions of the field experiment:

$$
\mathrm{G}_{\text {in.air }}=0.34 \mathrm{~kg} / \mathrm{sec}, \quad \mathrm{P}_{\text {in.air }}=1176798 \mathrm{~Pa} \text {, }
$$
$\mathrm{T}^{*}{ }_{\text {in.air }}=633 \mathrm{~K}$, $\mathrm{K}$.

$$
\mathrm{G}_{\mathrm{f} 1}=0.0025 \mathrm{~kg} / \mathrm{sec}, \mathrm{G}_{\mathrm{f} 2}=0.0074 \mathrm{~kg} / \mathrm{sec}, \mathrm{T}_{\mathrm{f} 1,2}=288
$$

Analysis of the most used turbulence models has shown that it is possible to take into account the curvature of current lines, rotational deformations and other effects of mass forces of a swirling flow or anisotropy of turbulence using:

- two-parameter models with correction for the curvature of current lines;

- differential models of Reynolds stresses.

The following turbulence models were selected for the computational study:

- two-parameter current lines with curvature correction: k- $\varepsilon$ CC, RNG k- $\varepsilon$ CC, SST CC;

- Reynolds stress: RSM BSL.

Calculations were performed in a stationary setting with account for heat exchange with the environment, without combustion, which corresponded to the first stage of the field experiment - "cold blowing", while the fuel supply channels were supplied with air with the flow rates and temperature corresponding to the flow rates and temperature of the fuel gas in the field experiment. 
The change in air heat capacity as a function of temperature was given in the form of a table, changes in viscosity - in accordance with the Sutherland equation. To assess the stability and convergence of the calculation, the flow imbalances at the inlet and outlet of the calculated area, as well as the values of the total pressure drop were tracked. The convergence of the calculation was considered achieved when the pressure losses were established, and the flow imbalances did not exceed $0.1 \%$. To determine the values of gas dynamic parameters obtained as a result of numerical experiment (averaged by mass flow rate), a control cross-section was created. The position of the control section geometrically corresponds to the position of the middle zone section of the single-burner compartment in which the full pressure and full temperature sensors are located (see Fig. 2). The control section for determining the calculated gas dynamic parameters is shown in figure 8 .

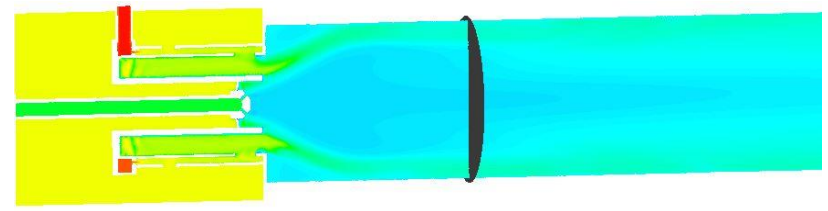

Figure 7. Control section for determining full pressure and full temperature

The results of gas dynamic calculations are presented in table 2

Table 2. Results of gas dynamic calculations

\begin{tabular}{|l|l|l|l|l|l|}
\hline $\begin{array}{c}\text { Turbulence model/ } \\
\text { Parameter }\end{array}$ & \multicolumn{1}{|c|}{$\begin{array}{c}\mathrm{P}^{*} \\
\mathrm{~Pa}\end{array}$} & $\begin{array}{c}\Delta \mathrm{P}^{*} \\
\%\end{array}$ & $\begin{array}{c}\mathrm{T}^{*} \\
\mathrm{~K}\end{array}$ & $\begin{array}{c}\Delta \mathrm{T}^{*} \\
\%\end{array}$ & $\begin{array}{c}\sigma^{*} \\
\%\end{array}$ \\
\hline $\mathrm{k}-\varepsilon$ CC & 1170910.03 & +3.43 & 629.88 & +1.3 & 0.5 \\
\hline k- $\varepsilon$ RNG CC & 1167853.41 & +3.16 & 626.77 & +0.8 & 0.76 \\
\hline SST CC & 1134004.23 & +0.17 & 625.28 & +0.56 & 3.63 \\
\hline RSM BSL & 1162419.43 & +2.68 & 629.13 & +1.18 & 1.22 \\
\hline
\end{tabular}

$\mathrm{P}^{*}, \mathrm{~T}^{*}$ - total pressure and temperature in the control section of the calculated area;

$\Delta \mathrm{P}^{*}, \Delta \mathrm{T}^{*}$ - deviations from the experimental values in $\%$;

$\sigma^{*}=\left(\left(\mathrm{P}_{\text {in.air }} \mathrm{P} *\right) / \mathrm{P} *_{\text {in.air }}\right) \times 100 \%$ - total pressure loss in $\%$.

Analysis of the calculation results showed that all the turbulence models used overestimate the values of the total temperature and total pressure in comparison with the experimental data.

The smallest deviation from the experimental data was given by the calculation using the SST SS model, which was adopted for the final physical and mathematical model.

Figures 8-11 show the velocity distribution fields in the longitudinal section of the single-burner section for each turbulence model.

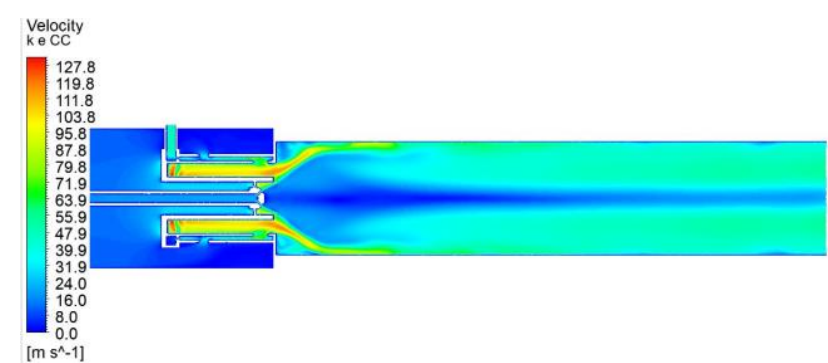

Figure 8. Velocity distribution field for the k- $\varepsilon \mathrm{CC}$ turbulence model

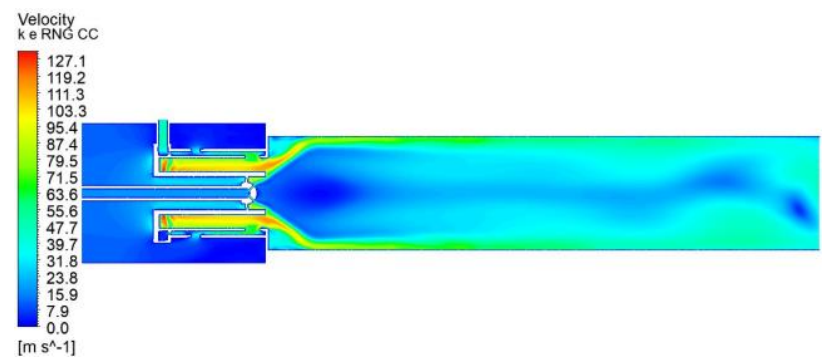

Figure 9. Velocity distribution field for the turbulence model k- $\varepsilon$ RNG CC

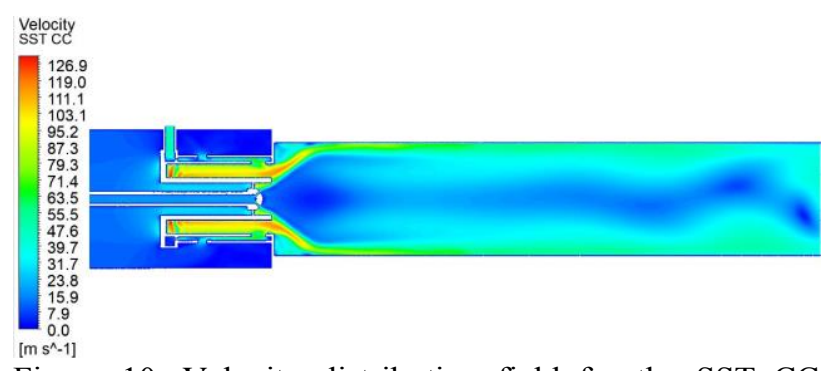

Figure 10. Velocity distribution field for the SST CC turbulence model 


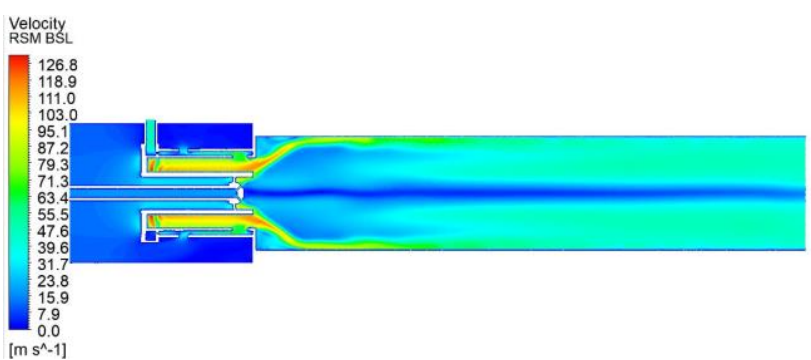

Figure 11. Velocity distribution field for the RSM CC turbulence model

At the second stage, calculations were performed considering heat exchange with the environment, considering combustion and radiation, which corresponded to the conditions of the second stage of the field experiment - fire tests. Analysis of the combustion models presented in ANSYS CFX showed their differences in the approach to chemical reactions simulation and the permissible size of chemical kinetics mechanism.

The following combustion models were selected for the computational study:

EDM, FRC/EDM, Laminar Flamelet with PDF and BVM.

The radiation models presented in ANSYS CFX were analyzed and the Monte Carlo model was chosen as the most suitable because it is the only one that allows simulating radiant heat exchange not only "wall-wall" and "wall-flow", but also "flowflow".

The calculations were performed in a stationary setting. To assess the stability and convergence of the calculation, the unbalances of the inlet and outlet flow rates, the values of the total pressure drop and the values of the total temperature at the outlet of the calculated area were tracked. The convergence of the calculation was considered as achieved when the pressure losses and the total temperature values

Table 3. Results of calculations $0.1 \%$. table 3. at the outlet from the calculated area were established, and the flow imbalances did not exceed

The chemical kinetics mechanisms WD2 NO PDF and WGS NO PDF were used for the combustion models EDM and FRC/EDM, for the combustion models Flameletwith PDF and BVM using the CFX-RIF program, a Flamelet library was created based on chemical kinetics mechanism Grimech 3.0. To determine the calculated values of the substances' concentrations in the combustion products, a section was created on which the control points for measurement are located. The position of the control points corresponds geometrically exactly to the position of the gas sampling intakes for the gas analyzer (see Fig. 2). The calculated results of measurements at five control points were averaged as well as during the field experiment. The mass flow averaged values of the total temperature were determined in the control plane described earlier (see Fig. 8). The cross section with reference points for determining the calculated values of the concentration of substances in the combustion products is shown in figure 12 .

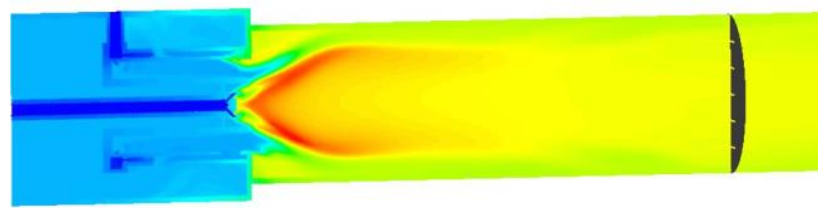

Figure 12. Control points for measuring the concentration of substances in combustion products

The results of the calculations are presented in

\begin{tabular}{|l|l|l|l|l|}
\hline $\begin{array}{c}\text { Combustion model, chemical kinetics } \\
\text { mechanism /Parameter }\end{array}$ & \multicolumn{1}{|c|}{$\mathrm{T}$} & \multicolumn{2}{c|}{$\begin{array}{c}\Delta \mathrm{T}^{*} \\
\mathrm{~K}\end{array}$} & \multicolumn{2}{c|}{$\begin{array}{c}\mathrm{O}_{2 \mathrm{~V}} \\
\%\end{array}$} & $\begin{array}{c}\Delta \mathrm{O}_{2 \mathrm{~V}} \\
\%\end{array}$ \\
\hline EDM, WD2 NO PDF & 1793.6 & +3.43 & 10.176 & -3.28 \\
\hline EDM, WGS NO PDF & 1781.1 & +2.75 & 10.182 & -3.22 \\
\hline FRC/EDM, WD2 NO PDF & 1742.4 & +0.6 & 10.46 & -0.58 \\
\hline FRC/EDM, WGS NO PDF & 1726.5 & -0.32 & 10.588 & +0.63 \\
\hline Laminar Flamelet with PDF & 1711.2 & -1.2 & 11.026 & +4.6 \\
\hline \multicolumn{1}{|c|}{ BVM } & 1848.04 & +6.7 & 10.07 & -4.23 \\
\hline
\end{tabular}

$\mathrm{T}^{*}$ - total temperature in control section of calculated area;

$\mathrm{O}_{2} \mathrm{v}$ - volume oxygen content in combustion products averaged by results of measurements at the control points of calculated area;

$\Delta \mathrm{T}^{*}, \Delta \mathrm{O}_{2} \mathrm{~V}$ - deviations from experimental values. 
All combustion models used, except BVM, give admissible deviations $(\leq 5 \%)$ of the mean integral values of the considered parameters from the experimental data, the smallest deviations were shown by the calculation using the FRC/EDM combustion model in combination with the WGS NO PDF chemical kinetics mechanism. The FRC/EDM combustion model with the WGS NO PDF chemical kinetics mechanism was accepted as finally validated for the final physical and mathematical model of the burner device under study.

The Laminar Flamelet with PDF combustion model shows the flame (see Fig. 17) in those areas of the burner devise where it is physically impossible in the considered mode, which allows to conclude that the Laminar Flameletwith PDF combustion model is completely unsuitable for simulating processes in this type of burner device; because its use will lead to large inaccuracies when calculating the thermal state of structural elements and when calculating the chemical composition of combustion products.

Figures 13-18 show the distribution fields of static temperature in the longitudinal section of a single-burner compartment when using different combustion models.

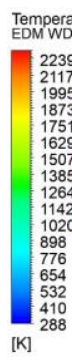

Figure 13. Temperature distribution field for the EDM combustion model with the WD2 NO PDF chemical kinetics mechanism

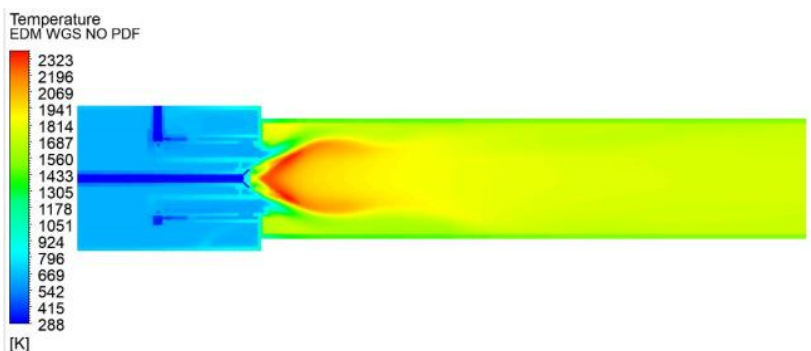

Figure 14 - Temperature distribution field for the EDM combustion model with the WGS NO PDF chemical kinetics mechanism

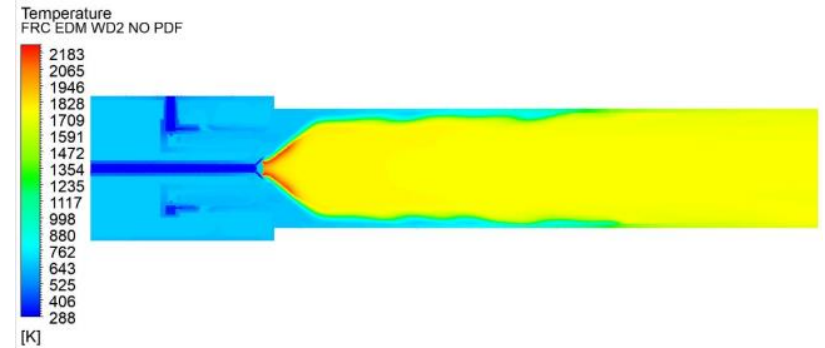

Figure 15. Temperature distribution field for the FRC/EDM combustion model with the WD2 NO PDF chemical kinetics mechanism

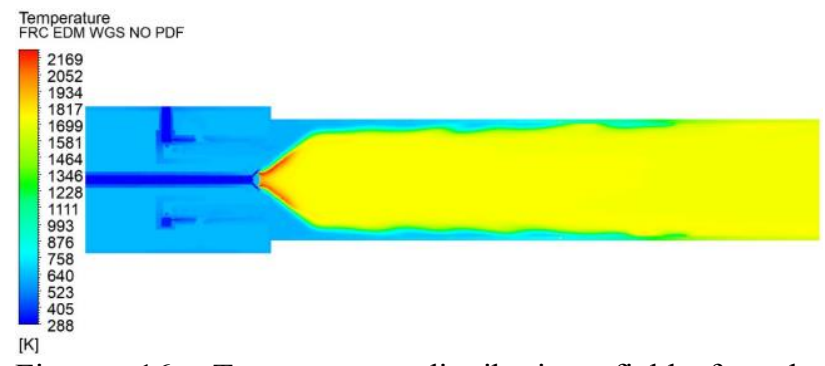

Figure 16. Temperature distribution field for the FRC/EDM combustion model with the WGS NO PDF chemical kinetics mechanism

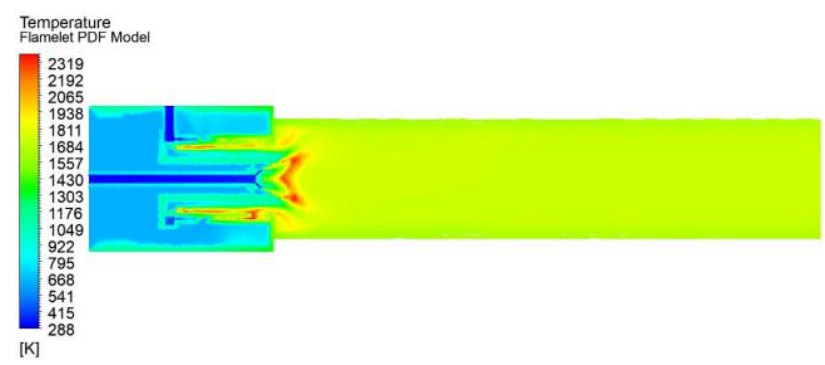

Figure 17. Temperature distribution field for the Laminar Flamelet with PDF combustion model

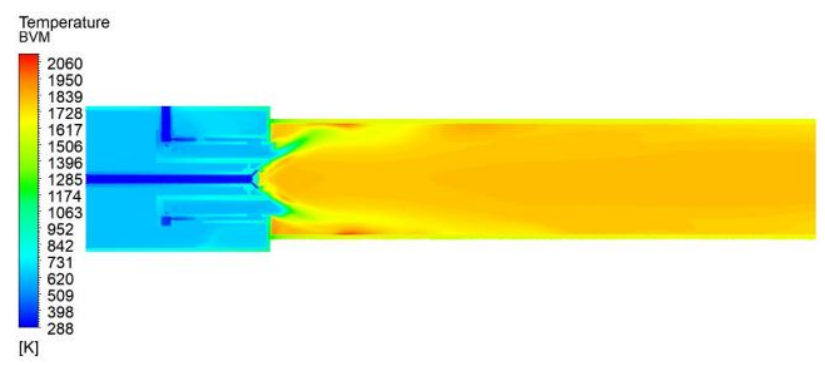

Figure 18. Temperature distribution field for the BVM combustion model

The final physical and mathematical model of the studied burner device formed according to the described method consists of the following mathematical models of physical processes:

- SST CC turbulence model;

- FRC/EDM combustion model;

- WGS NO PDF chemical kinetics mechanism;

- Monte-Carlo radiation model.

To test the developed method, a calculated study of the content of $\mathrm{NO}$ and $\mathrm{CO}$ in the combustion products of the single-burner section for the 
following mode was performed on the formed physical and mathematical model of the burner device:

- total air pressure at the burner device inlet - 1 $667130 \mathrm{~Pa}$;

- total air temperature at the burner device inlet $703 \mathrm{~K}$;

- air consumption - $0.44 \mathrm{~kg} / \mathrm{sec}$;

- methane consumption in the first circuit $0.0037 \mathrm{~kg} / \mathrm{sec}$;

- methane consumption in the second circuit $0.0095 \mathrm{~kg} / \mathrm{sec}$;

- methane temperature for the first and second circuits - $288 \mathrm{~K}$;

- ambient air temperature - $288 \mathrm{~K}$.

The following was obtained as a result of the calculation:

- NO content (reduced to $15 \%$ ) $26.131 \mathrm{ppm}$;

- CO content (reduced to 15\%) $23.812 \mathrm{ppm}$.

As a result of the field experiment on the singleburner section, the following results were obtained:

- NO content (reduced to 15\%) $24.96 \mathrm{ppm}$;

- CO content (reduced to $15 \%) 25.3 \mathrm{ppm}$.

The maximum amount of discrepancies between the calculated data and the experimental data was $4.8 \%$.

\section{Discussions}

The model developed according to the proposed method is an effective tool for optimizing the studied burner device and for designing a new one based on it.

The application of the proposed method of the physical and mathematical model developing for calculating flow parameters for the flow part of the burner devices reduces the time of design work and the volume of experimental refinement by replacing part of the field tests with numerical experiments.

The reliability of the results obtained is achieved by using the fundamental laws of conservation of mass, momentum and energy with justification for the choice of a particular physical model while simultaneously controlling the convergence of the mathematical model solution, using the certified software package ANSYS CFX, verified on a set of problems used to assess the quality of physical and mathematical combustion models, by matching the calculated data with the results of field experiments conducted using certified measuring equipment.

\section{Conclusions}

As a result of the research, an urgent scientific problem was solved that is important for identifying the mechanisms of mass, momentum and energy transfer during convection, radiation, complex heat exchange and physico-chemical transformations using numerical modeling in burner devices of lowemission combustion chambers of gas turbine engines and the following results were obtained:

1. The burner device is experimentally studied in two operating modes; the results of which and the results of numerical experiments are used to validate mathematical models used to model the physical processes that occur during combustion.

2. A physical and mathematical model was formed based on the averaged Navier-Stokes equations, the SST turbulence model with correction of the curvature of flow lines, the FRC/EDM combustion model with the WGS NO PDF chemical kinetics mechanism, the Monte-Carlo radiation model and the model of heat transfer with walls, allowing transfer of mass, momentum and energy in a multicomponent chemically reactive mixture in a limited swirling flow with combustion reactions.

3. The method for modeling gas dynamic processes in low-emission combustion chamber burner devices was developed and tested on the basis of the proposed physical and mathematical model, which allows to correctly reflect the parameters of the swirling flow, the formation of the flame front, as well as to calculate the chemical composition of combustion products in the flow and the thermal state of the structure walls.

\section{Acknowledgment}

This work was supported by the Ministry of Science and Higher Education of the Russian Federation as a part of the Federal program "Research and development in priority areas of development of the scientific and technical complex of Russia for 20142020". Agreement on the provision of a grant in the form of subsidyNo. 075-15-2019-1710 dated December 2, 2019 (internal number 05.608.21.0275). Unique ID: RFMEFI60819X0275.

\section{References:}

[1] M. M. Abou-Ellail, K. R. Beshay, M. S. Mansour. A flamelet model for premixed methane-air flames. Combustion Science and Technology, Vol. 153, issue 1, 2000, pp. 223245. DOI: $10.1080 / 00102200008947262$.

[2]N. Peters, Turbulent Combustion, Cambridge monographs on mechanics, Cambridge University Press, 2000.

[3]F.A. Williams, Recent Advances in Theoretical Descriptions of Turbulent Diffusion Flames. Turbulent Mixing in Nonreactive and Reactive 
Flows. Edited by S.N.B. Murthy, New York:Plenum Press, 1975, pp.189-208.

[4]K.N.C. Bray, P.A. Libby, F.A. Williams, Turbulent flows with premixed reactants, Turbulent Reacting Flows. Edited by Topics in Applied Physics, Vol 44,1980, pp. 115-183.

[5] V.L. Zimont, W. Polifke, M. Bettelini, W. Weisenstein, An efficient Computational Model for Premixed Turbulent Combustion at High Reynolds Numbers Based on a Turbulent Flame Speed Closure, J. Engineering for Gas Turbines and Power (Transactions of the ASME), Vol 120, 1998, pp. 526-532.

[6] V.L. Zimont, Gas Premixed Combustion at High Turbulence. Turbulent Flame Closure Combustion Model, Proceedings of the Mediterranean Combustion Symposium, Instituto di RicherchesullaCombustione, 1999, pp. 11551166.

[7] V.L. Zimont, F. Biagioli, S. Khawar, Modelling turbulent premixed combustion in the intermediate steady propagation regime, Progress in Computational Fluid Dynamics, Vol. 1, 2001 pp.14-28.

[8]D. Dannecker, B. Noll, M. Hase, W. Krebs, K.U. Schildmacher, R. Koch, M. Aigner, Impact of Radiation on the Wall Heat Load at a Test Bench Gas Turbine Combustion Chamber: Measurements and CFD Simulation, Proceedings of GT2007 ASME Turbo, GT2007-27148, 2007, pp. 11.

[9]P.J. Stuttaford, P.A. Rubini, Assessment of a Radiative Heat Transfer Model for a New Gas Turbine Combustor Preliminary Design Tool, 35th Aerospace Sciences Meeting \& Exhibit, AIAA Paper 97-0294, 1997, pp. 12.

[10] A.Yu. Snegirev, Statistical modeling of thermal radiation transfer in buoyant turbulent diffusion flames, Combustion and Flame, Vol 136, 2004 pp. 51-71.

[11] T. Peeters. Numerical Modeling of Turbulence Natural-Gas Diffusion Flames, PhD thesis, Delft Technical University, Delft, The Netherlands, 1995, pp. 263.

[12] D.B. Spalding, Mixing and chemical reaction in steady confined turbulent flames, 13th Symp. (Intl.) Comb., Combustion Institute, Pittsburgh, 1970, pp. 649.

[13] B. F. Magnussen, B. H. Hjertager, On mathematical modeling of turbulent combustion with special emphasis on soot formation and combustion, Sixteenth Symp. (Int.) on Combustion, Combustion Institute, Pittsburgh, 1976, pp. 719.
[14] B.G. Mingazov, V. B. Yavkin, A. N. Sabirzyanov, A. V. Baklanov. Analysis of the combustion models applicability for calculating the multi-nozzle combustion chamber of GTE, Bulletin of the Samara State Aerospace University, No. 5 (29), 2011.

[15] Yu. I. Torba, S. I. Plankovsky, O. V. Trifonov, E. V. Tsegelnik, D. V. Pavlenko. Modeling of the combustion process in GTE flare igniters, Aviation and space technique and technology, No. 7 (159), 2019.

[16] V. S. Yegorychev, L. S. Shabliy, V. M. Zubanov. Modeling of in-chamber low-thrust engine workflow on gaseous oxygen and hydrogen in ANSYS CFX, Samara: Publishing House of the Samara, University, 2016, pp. 136.

\section{Contribution of individual authors to the creation of a scientific article (ghostwriting policy)}

O.I. Klyavin has organized the researches

E.V.Gaultier was responsible for the investigation of the turbulence models, combustion models and chemical kinetics mechanisms

A.A. Schengals has made the literature review

A.S. Tikhonov has carried out the CFD simulations

\section{Sources of funding for research presented in a scientific article or} scientific article itself

This work was supported by the Ministry of Science and Higher Education of the Russian Federation as a part of the Federal program "Research and development in priority areas of development of the scientific and technical complex of Russia for 20142020". Agreement on the provision of a grant in the form of subsidyNo. 075-15-2019-1710 dated December 2, 2019 (internal number 05.608.21.0275). Unique ID: RFMEFI60819X0275.

\section{Creative Commons Attribution License 4.0 (Attribution 4.0 International, CC BY 4.0)}

This article is published under the terms of the Creative Commons Attribution License 4.0 https://creativecommons.org/licenses/by/4.0/deed.en US 